\title{
CAMBIOS RECIENTES EN LA INDUSTRIA CASTELLONENSE DEL CALZADO: REFLEXIONES SOBRE UNA CRISIS
}

\author{
Rafael Viruela Martínez
}

\section{INTRODUCCIÓN}

En 1982, según datos facilitados por el I.N.S.S., la industria del calzado ocupaba en Castelló «oficialmente» a 2.749 trabajadores directos (sin tener en cuenta a los trabajadores sumergidos), distribuidos en un total de 39 establecimientos. Es, pues, un sector caracterizado por la elevada intensidad de mano de obra, en su mayor parte sin una elevada cualificación profesional, así como por su fuerte grado de concentración espacial: la Plana es la comarca que concentra la mayor parte de los establecimientos $(84,6 \%)$ y de los productores $(97,5 \%)$, especialmente en el centro fabril de la Vall d'Uixó, que en ese año contaba con 28 empresas y con 2.477 operarios. A escala estatal esta centralización se aprecia en el País Valencià, que en 1979 contaba con más de la mitad de las empresas españolas y con el 60\% del empleo ${ }^{1}$.

Durante años -en la segunda mitad de los sesenta y comienzos de los setenta- el sector español conoció un período de esplendor con un progresivo aumento de la producción y de las exportaciones. Este auge se debió a la competitividad de nuestros productos basada en la elevación de los salarios en los países desarrollados (U.S.A., R.F.A., etc.) hacia los que se dirigían nuestros zapatos, mientras el coste de la mano de obra española era relativamente bajo $^{2}$. Desde entonces, la situación se ha modificado de forma sustancial, las

1 YBARRA PÉREZ, J. A.: «La reestructuración espontánea de la industria del calzado español: aspectos laborales y territoriales», Boletín de Estudios Económicos, n. ${ }^{\circ}$ 117, vol XXXVII, Universidad de Deusto, Bilbao, diciembre 1982, p. 490.

2 BERNABÉ MAESTRE, J. M.: «Factores de localización y crisis de la industria valenciana del calzado», Panorama Bursátil, n. ${ }^{\circ}$ 6, octubre 1977, p. 72. 
devaluaciones del dólar que suponían revaluaciones de la peseta y la imposición de derechos compensatorios a la importación en Estados Unidos de calzado español, marca el inicio de una crisis que exigía un acelerado proceso de reestructuración del sector ${ }^{3}$, se han incrementado los costes y se han elevado los precios de venta al por mayor. La situación se ha visto agravada por la aparición, en los últimos años, de países productores en vías de desarrollo (asiáticos y sudamericanos), con bajos costes de producción sobre la base de la baja retribución de la mano de obra y la abundancia de materias primas, lo que sitúa a nuestra producción en franca desventaja en el mercado internacional; los efectos se han dejado sentir también en nuestro mercado interior. Como consecuencia nuestras exportaciones disminuyen al tiempo que aumentan las importaciones de forma constante. Así, según datos del Instituto Español del Calzado $^{4}$, en el primer trimestre de 1980 las exportaciones se redujeron en un tercio con respecto al mismo período del año anterior; en cuanto a importaciones, en 1979 se duplicó la cifra de pares importados en 1978. Desde mediados de los setenta la producción española ha disminuido de forma progresiva, en 1981 se produjo aproximadamente un $27 \%$ menos que en $1976^{5}$.

Frente a la competencia de los nuevos países productores, los más avanzados -Italia, Francia, etc.-, con el fin de mantener sus posiciones en el mercado, potencian la investigación tecnológica, tratando de encontrar innovaciones: maquinaria, materiales, etc., con resultados positivos. En definitiva, nos encontramos en franca desventaja ante unos países competitivos en altas producciones a bajo precio, y otros en calidad y diseño. Con el fin de paliar esta situación, la Administración española ha manifestado el deseo de reactivar el sector; ahí están, por ejemplo, la Comisión Tripartita (empresarios, trabajadores, Administración) de 1980; el Plan de Reconversión para la fabricación del calzado e industria auxiliar, de 1982. Las medidas administrativas para lograr la reconversión del sector han llegado en un momento en que la degradación del sistema productivo es tal que quizás sea tarde para reactivarlo, aunque «más vale tarde que nunca».

La falta de medidas adecuadas en su momento hace que la crisis sea, desde mediados de los setenta, cada vez más aguda, tal como se puede apreciar en el siguiente cuadro donde se recogen los expedientes de regulación de empleo presentados por las empresas en los últimos años, y en el elevado número de trabajadores afectados por esos expedientes.

3 Caja de Ahorros de València, INFORMACIONES 78, 1979, p. 115.

4 MINISTERIO DE INDUSTRIA Y ENERGÍA: «Editorial», Economía Industrial n. ${ }^{\circ}$ 195, marzo 1980, p. 6.

$5 \quad$ YBARRA PÉREZ, J. A.: ob. cit., p. 488. 


\section{CUADRO I}

Número de expedientes de regulación de empleo y trabajadores afectados en la provincia de Castelló

\begin{tabular}{ccc}
\hline Año & $N^{o}$ de expedientes & $\frac{N .^{o} \text { de trabajadores }}{127}$ \\
\cline { 2 - 3 } 1974 & 1 & 87 \\
1975 & 1 & 1 \\
1976 & 1 & 694 \\
1977 & 3 & 304 \\
1978 & 1 & 1.202 \\
1979 & 13 & 2.323 \\
1980 & 16 & 254 \\
1981 & 11 & 1.515 \\
1982 & 5 & 1.304 \\
1983 & 7 & 1.758 \\
\cline { 2 - 2 } Total & 31 & \\
& & 9.569 \\
\hline
\end{tabular}

Fuente: Conselleria de Sanitat, Treball i Seguretat Social, Delegació Territorial de Castelló.

Elaboración propia.

Las escasas medidas, inoperantes y tardías, han hecho que la crisis haya sido cada año más intensa, especialmente en los años ochenta, cuando se incrementa el número de expedientes de forma extraordinaria, en sólo cinco años -de 1980 a 1984- fueron presentados ante la Delegación Territorial de Trabajo nada menos que 70 expedientes. El mayor número de expedientes corresponde a suspensión de actividad, un total de 74 de los 90 que se presentaron entre 1974 y 1984, aunque el mayor número de trabajadores afectados lo han sido por reducción de jornada, entre 1980 y 1984 se vieron implicados en esta situación un total de 4.405 operarios. La extremada concentración espacial a la que hemos hecho referencia hace que la crisis se plantee con mayor virulencia en la Vall d'Uixó; de los 90 expedientes sólo cinco corresponden a empresas instaladas en otras localidades. En aquel centro zapatero la crisis ha sido especialmente intensa debido a las escasas alternativas de empleo debido a su especialización en la industria del calzado, a la que -en 1975- se dedicaba uno de cada dos activos secundarios.

Como quiera que el interés público por la industria del calzado se ha manifestado con cierto retraso, han sido los empresarios quienes han tenido que adaptar su estructura productiva con el fin de mantener una cierta competitividad. Ante la crisis actual, las estrategias empleadas por nuestros empresarios han sido la utilización de trabajo clandestino y la descentralización productiva, con el fin de reducir sus costes; estrategias a las que el profesor 
Ybarra $^{6}$ llama «reestructuración espontánea» en un deseo de los empresarios de mantenerse dentro de un sector en crisis. El objeto de este estudio es poner de relieve cuál ha sido la actuación del sector en los últimos años; somos conscientes de que no vamos a descubrir nada nuevo a los interesados, empero, les puede ofrecer una visión de conjunto. En este sentido nuestro papel -modesto- debe ser el de dar a conocer lo que está ocurriendo para que los implicados reflexionen y adopten las medidas oportunas para lograr la verdadera y necesaria reestructuración de un sector que está atravesando por una profunda crisis.

\section{LA ECONOMÍA SUMERGIDA}

La industria del calzado ha venido utilizando tradicionalmente mano de obra oculta, trabajo negro, que se ha visto incrementado de forma considerable a partir de la crisis de los años setenta. Este trabajo no consta en las estadísticas oficiales, de ahí que la principal dificultad para constatar su alcance sea la falta de fuentes por la ausencia de información oficial y por el escaso interés que muestran los afectados en hablar del tema por el temor a que sus declaraciones puedan privarles de este tipo de trabajo, que constituye un complemento de la economía familiar, cuando no es -por suerte, en pocos casos- la única fuente de ingresos; menor interés muestran los empresarios por el lógico recelo de quien incumple una norma.

Aunque no puede conocerse exactamente el volumen que alcanza el clandestinaje en el sector calzado, diversos estudios ${ }^{7}$ han puesto de manifiesto la considerable expansión que ha adquirido en fechas recientes, y que afecta principalmente -como así lo hemos constatado- a mano de obra femenina. Siguiendo al profesor Bernabé, que considera apropiada la distribución de los trabajadores del sector en un 50\% de varones y un 50\% de mujeres, se puede intentar evaluar subinscripciones. En base a los listados facilitados por la empresa «IMEPIEL, S.A.» y por el I.N.S.S., en 1982 el sector provincial del calzado ocupaba a unos 1.900 varones y a unas 850 mujeres $^{8}$; es decir, según las estadísticas disponibles debemos suponer que las mujeres sumergidas rondaban el millar, lo que representa entre el 36 y $38 \%$ de la ocupación total, por-

6 YBARRA PÉREZ, J. A.: ob. cit., pp. 483-504.

7 Véanse a este respecto los trabajos de BERNABÉ MAESTRE, J. M.: La industria del calzado en el Valle del Vinalopó, Departamento de Geografía, Universidad de València, 1976, 236 pp.; VIRUELA MARTÍNEZ, R.: «El trabajo a domicilio en la industria del calzado de la Vall d'Uixó», Estudis Castellonencs, n. ${ }^{\circ}$ 1, Diputació de castelló, 1983, pp. 401-409.

El fenómeno ha sido estudiado en otros países, especialmente en Italia, donde el trabajo a domicilio ha alcanzado un extraordinario volumen. Véase, por ejemplo, ESPOSITO, L.: «Il settore calzaturiero», Studi Economici, rivista quadrimestrale a cura della Facoltà di Economia e Comercio dell'Università di Napoli, 1977, pp. 111-146; o, FRIGENI, R. y TOUSIJN, W.: L'Industria delle calzature in Italia, Il Molino, Bologna, 1976, pp. 115-116.

8 El hecho de no ofrecer cifras exactas se debe a que, en los mencionados listados, en algunas empresas no se distinguía entre varones y mujeres. Con todo, las cifras que presentamos no deben estar muy alejadas de la realidad. 
centaje muy superior al estimado por el profesor Bernabé (23\% en 1980) para el conjunto del sector español ${ }^{9}$. Esta estimación no es -y tampoco lo pretende- exhaustiva, ya que no incluye a los trabajadores ocupados en talleres clandestinos; si los tuviésemos en cuenta, el porcentaje de trabajadores sumergidos sería mucho más elevado.

En el calzado, el trabajo a domicilio se orienta fundamentalmente a la fase de aparado, tradicionalmente ejecutada por mujeres, y para la que se requiere un elevado número de operarios. En este sentido, la presencia de la mujer en la fábrica debería ser mucho mayor, y, como acabamos de precisar, no lo es debido a la sistemática descentralización de estas operaciones a domicilio, que han venido fomentando todo tipo de empresarios, grandes y pequeños, aunque se puede mantener un mínimo de actividad en la fábrica. El caso más espectacular, por ser la que mayor número de trabajadores tiene fuera de la fábrica, es el de «IMEPIEL, S.A.», aunque puede afirmarse que no hay empresa que no recurra a cualquier modalidad de trabajo clandestino, bien con trabajadores a domicilio, bien con ayuda de trabajadores que tienen su puesto de trabajo legal en otra empresa, o bien contratando ciertas fases del proceso productivo a empresas sumergidas en parte o en todo.

En el cuadro II aparece la relación de intermediarios que trabajan para la mayor empresa española del calzado. Hay un total de 49 proveedores de cortes aparados, la mayoría residentes en la Vall y trabajadores de la empresa o familiares de éstos, sólo catorce no tienen relación con la empresa (de ellos, tres son fábricas). La mayoría de los proveedores, un total de 36, son exclusivos de «IMEPIEL, S.A.», el resto trabaja además para otras empresas del sector. Esta organización de la producción ha dado lugar a la figura de los intermediarios, por lo general varones (más de la mitad), que reparten con sus vehículos el cuero cortado a las casas particulares, volviendo al día siguiente, o a los pocos días (ya que un mismo corte puede recorrer varias casas), a recoger los cortes ya aparados.

Aunque los datos se refieren a una sola empresa (la mayor de todas), nos ofrecen una clara imagen del volumen que alcanza el trabajo sumergido en la industria del calzado, máxime cuando a esta empresa le suministran otras tres que, a su vez, practican el clandestinaje, y cuando trece de los intermediarios suministran también a otras empresas; además, téngase presente que el total es de 49 intermediarios, cuando en el interior del establecimiento trabajan menos de doscientas mujeres en la sección de aparado.

Desde hace unos años está incrementándose el número de talleres clandestinos, lo cual representa un nuevo tipo de sumersión, constituyendo una

9 BERNABÉ MAESTRE, J. M.: «La economía oculta», Cuadernos de Geografía, n.o 29, Departamento de Geografía, València, 1981, p. 222.

En 1979 Ybarra calculó que en el sector zapatero español, «el trabajo marginal» afecta a un 30\% del empleo, véase YBARRA PÉREZ, J. A.: «Economía subterránea, reflexiones sobre la crisis económica en España», Economía Industrial, n. ${ }^{\circ}$ 218, Servicio de publicaciones del Ministerio de Industria y Energía, 1982, p. 36. 


\section{CUADRO II}

Relación de intermediarios que trabajan para «IMEPIEL, S. A.»

Domicilio
La Vall d'Uixó
Fondeguilla
Caudete

Relación con la empresa

Familiares de trabajadores

Trabajadores

Sin relación con la empresa

Intermediarios exclusivos

Intermediarios de varias fábricas

Varones

Mujeres

Fábricas

\section{N. ${ }^{o} \mathrm{de}$}

intermediarios

42

4

$\frac{3}{49}$

23

11

15

36

13

26

20

3

TOTAL INTERMEDIARIOS

Fuente: elaboración propia.

competencia desleal a los establecimientos legales, que hasta estos momentos tenían en el trabajo a domicilio un complemento a su producción. Plantas bajas de las viviendas, pequeños almacenes, garajes, etc., se han transformado en talleres clandestinos de difícil control, sobre todo en barrios periféricos («Carbonaire», «Toledo», ...) de la Vall d’Uixó. Todos los habitantes de la localidad, relacionados o no con el sector, saben de la existencia de estos «talleres piratas», de manera que resulta un tanto contradictorio llamar clandestinos a unos establecimientos que todo el mundo conoce. Se puede decir que no hay taller clandestino que produzca todo el zapato de principio a fin. Los cortes de los que al final saldrá el zapato recorren varios talleres para cada uno de los procesos de fabricación; siendo, en último término, una comercializadora la que se encarga de la venta del producto.

Llegados a este punto conviene preguntarse a qué obedece el trabajo sumergido del calzado, en progresivo aumento en los últimos años. La mayoría de los autores coinciden en afirmar que se trata de una adaptación de los empresarios a la crisis del sector, agravada por la competencia de nuevos países productores, permitiéndoles reducir el coste final del producto. A estas razones de los empresarios, en las que -como veremos- influyen sus propias ca- 
racterísticas y las de sus establecimientos, debe añadirse las dificultades de los trabajadores para encontrar un empleo, viéndose irremediablemente arrastrados hacia el clandestinaje, convirtiéndose, de esta forma, en cómplices de los empresarios.

\section{LA REDUCCIÓN DE COSTES EN LAS EMPRESAS}

En la industria española del calzado los elementos que más influyen en el coste de la producción son la mano de obra y las materias primas, que constituyen más del $75 \%$ o del valor total, correspondiendo casi un tercio a sueldos, salarios y Seguridad Social ${ }^{10}$. Por esta razón los precios de nuestra manufactura en el mercado deben ser superiores a los que pueden ofrecer otros países con mano de obra barata y abundancia de materias primas. Nuestros empresarios intentan obtener una estructura de costes que les permita ser competitivos, recurriendo al trabajo clandestino con el objetivo de abaratar la producción; como dice Ybarra, ante la posibilidad de desaparecer la reacción es la de ocultarse ${ }^{11}$. Si unos empresarios practican el clandestinaje, lo más normal será la imitación por parte de otros. Esta ha sido la reacción de los empresarios de nuestra provincia; para ellos se trata de «una enfermedad necesaria» que les permite mantener una cierta competencia al ser un fenómeno generalizado en otras regiones zapateras (españolas y extranjeras), y afirman que: «si, incluso, con mano de obra clandestina tenemos problemas porque no somos competitivos, sin estos trabajadores aún sería peor».

La reducción de costes que se obtiene con la utilización del trabajo clandestino es considerable, a tal punto que el simple ahorro que representa el no tener que pagar la Seguridad Social de los trabajadores reduce el coste del trabajo en aproximadamente un 30\%, en este sentido reconocemos con Ruiz Álvarez ${ }^{12}$ la discriminación a la que están sometidas las empresas del calzado con relación a otras actividades no tan intensivas en mano de obra, ya que la cotización se efectúa en base a los salarios y no sobre el valor añadido bruto de las empresas.

Además de no pagar a la Seguridad Social, el salario que puede obtener un trabajador clandestino es inferior al de un trabajador en fábrica, por cuanto que no se pagan vacaciones, pagas extras, gratificaciones, etc. El empresario ahorra también el salario del personal administrativo que no hay en el trabajo sumergido. Junto a estas razones importantes, hay otras que asimismo representan una reducción del coste final del producto, ya que el trabajo a domicilio permite a la empresa ahorrar gastos de instalación e infraestructura, tampoco gasta energía y algunas materias primas. En efecto, la mayor parte

10 PREVASA: La industria valenciana en el umbral de los «80», Caja de Ahorros de València, 1982, p. 135.

11 YBARRA PÉREZ, J. A.: «Economía subterránea...», ob. cit., p. 38.

12 RUIZ ÁlVAREZ, J. L.: «Algunas reflexiones sobre la financiación de la Seguridad Social», Información Comercial española, n. ${ }^{554}$, octubre 1979, pp. 19-20. 
de las mujeres que entrevistamos afirmaban que la máquina (Alfa o Adles, tipo industrial), la energía, el hilo, etc., son aportados por ellas, que también corren con los gastos de mantenimiento; en otros casos, la máquina y otros útiles son cedidos por la empresa, pero al trabajador se le descuenta del salario una determinada cantidad de dinero cada cierto tiempo en cuestión de amortización. En definitiva, con el trabajo sumergido muchos empresarios, en la actual situación de crisis, pueden seguir trabajando, lo que les sería muy difícil en caso de mantenerse en la legalidad. Debemos concluir afirmando que las prácticas ilegales se han convertido, hoy por hoy, en auténtico medio de supervivencia del empresario.

Esta actuación a espaldas de la Administración está propiciada por el peso de la pequeña empresa dentro del sector, con una base dimensional extremadamente débil, y por las propias características de los empresarios.

\section{ESTRUCTURA EMPRESARIAL}

Si atendemos a la dimensión media de los establecimientos, Castelló presenta una cifra muy elevada; en 1982 la distribución de los 2.749 trabajadores entre los 39 establecimientos fabriles daba una media de 70,5 operarios/fábrica. Visto de esta manera podría pensarse que la provincia dispone de un tipo medio de empresa de mayores dimensiones, con una plantilla media de productores superior a la media nacional y a la del País Valencià. No obstante, este valor pierde su significado por la existencia de una empresa de grandes dimensiones, que en el mismo año contaba con 1.965 trabajadores, es decir, con el 71,5\% de los productores provinciales; y la presencia de pequeñas empresas que emplean al resto de los productores. En 1982 más de la mitad de los establecimientos no superaban los diez operarios. Esta proporción de las empresas más pequeñas debe ponerse en relación con la crisis que ha venido afectando a las de mayores dimensiones (LA VALLENSE, S.A. e IMEPIEL, S.A.). Si con anterioridad -a comienzos de los setenta- las empresas un poco más grandes nacían de las más pequeñas ${ }^{13}$, ahora son éstas las que tienen su origen en las de mayores dimensiones; desde la crisis se ha invertido el proceso.

\section{CARACTERÍSTICAS DE LOS EMPRESARIOS. LA SUBCONTRATACIÓN}

Tal como puede apreciarse en el cuadro III, la mayor parte de los actuales empresarios del sector calzado en nuestra provincia, son antiguos alpargateros o hijos de éstos que han heredado el patrimonio familiar; más recientemente, también abundan los empresarios de extracción obrera, ex-operarios de las dos empresas de mayores dimensiones o de otras creadas a partir de éstas, que, de asalariados, se han convertido en empresarios, sin una adecuada formación profesional teórica.

13 VIRUELA MARTÍNEZ, R.: La Vall d’Uixó: un núcleo zapatero, tesis de licenciatura, Departamento de Geografía, València, octubre 1979, p. 97. 


\section{CUADRO III}

Origen de los empresarios del calzado en 1982

\begin{tabular}{lrr}
\multicolumn{1}{c}{ Procedencia } & Número \\
\cline { 1 - 1 } Antiguos alpargateros o hijos de éstos & & 20 \\
Ex-operarios & & 14 \\
Alpargateros y ex-operarios & 4 \\
Gerentes profesionales & 1 \\
\cline { 2 - 2 }
\end{tabular}

Total

Fuente: Listados del I. N. S. S., 1982, y entrevista directa. Elaboración propia.

En la actualidad, sólo una empresa cuenta con gerente profesional, se trata del mayor establecimiento del sector, perteneciente al patrimonio del Estado. Más de la mitad de las empresas están dirigidas por antiguos alpargateros, o por hijos, que han mantenido el taller familiar con escasas innovaciones técnicas, algunos continúan dedicándose a la producción de alpargatas, otros han derivado hacia el calzado vulcanizado; todos con productos destinados al mercado nacional. Sus establecimientos son los de menores dimensiones, los que conservan un marcado carácter artesano-familiar. Por su parte, alpargateros, o sus herederos, con la colaboración de profesionales cualificados del calzado, han fundado empresas (sólo cuatro) cuya producción se orienta hacia otras modalidades de calzado, junto con el vulcanizado. A este grupo de pequeños empresarios, provenientes de la vieja artesanía, se ha unido otro pequeño grupo constituido por asalariados de otras empresas de calzado a las que han abandonado; en la mayoría de los casos se han unido especialistas de distintos departamentos: uno de exportación, un patronista, un cortador, ...y con un pequeño capital han fundado fábricas, en total son 14 las empresas creadas por estos empresarios, que representan el 36\% del total. Están sostenidas -como ellos mismos reconocen- por la reducción de costes que obtienen al utilizar trabajadores clandestinos. En definitiva, el empresariado del calzado castellonense está integrado por hombres que se han formado a sí mismos, directores de estructuras industriales débiles, más prácticos que teóricos ${ }^{14}$. Las características de los empresarios repercuten en las del sector, son personas poco arriesgadas, reacias a innovaciones tecnológicas que amplíen y mejoren su capacidad productiva, prefiriendo, en cambio, el recurso a formas ilegales de trabajo.

14 Estas características han sido destacadas por Josep Picó al analizar las características del empresario industrial valenciano. Véase al respecto PICÓ, J.: «El empresario industrial», en Estructura Social al País Valencià, a cura de Rafael Ll. Ninyoles, Diputació de València, 1982, p. 612. 
Hay pocas empresas cuyos dirigentes tengan una clara visión de mercado. Estos son antiguos representantes de las grandes empresas, que en sus viajes al extranjero contactaban directamente con importadores y grandes cadenas de tiendas, de manera que cuando se han convertido en directores de su propia empresa lo han hecho sobre la base de una clientela asegurada ${ }^{15}$. Pero la mayoría de las empresas de reciente creación no han contado con esta circunstancia favorable, dependiendo de otras más aventajadas ${ }^{16}$. Las empresas fabricantes y comercializadoras de su producción y de la de otras fábricas de calzado, a las que deben el mayor volumen de sus ventas, muchas veces imitan zapatos extranjeros, casi siempre italianos; como ellos dicen «hacemos la marca y los modelos que los clientes nos mandan», «recogemos modelos de las tiendas que visitamos y con las informaciones de los clientes (grandes cadenas de tiendas e importadores con marca propia), variables según el ritmo de sus ventas, hacemos nuestros propios muestrarios», lo único que hacen es introducir algún pequeño detalle en el zapato que les sirve de referencia.

Aproximadamente el $80 \%$ de las empresas del sector trabajan para otras dedicadas principalmente a la comercialización. Se trata de pequeños empresarios que se ven obligados irremediablemente a la subcontratación por las características estructurales de sus establecimientos (en los que apenas se invierte), ya que al fabricante pequeño no le resulta rentable realizar todas y cada una de las acciones necesarias para comercializar sus productos; así como por las características de los propios empresarios que no cuentan con la preparación adecuada, no conocen el funcionamiento del mercado, ni tienen nociones de idiomas extranjeros.

\section{EL PARO COMO IMPULSOR DEL TRABAJO CLANDESTINO}

Como acabamos de comprobar los empresarios, dirigentes de establecimientos de dimensiones reducidas, sin una clara visión de mercado, usan y abusan del trabajo clandestino con el fin de mantener unos costes que les permitan competir. Pero, sin duda, la alarmante difusión que está alcanzando se ve favorecida por la actual situación del mercado de trabajo: el aumento del paro, la pérdida creciente de puestos de trabajo legales. Estamos convencidos

15 Hemos tenido oportunidad de entrevistar a dos de estos empresarios comercializadores. Uno de una fabrica productora de calzado, que en 1982 contaba con una plantilla de 21 trabajadores, dedicada ademas a la comercialización, con un volumen de exportación superior al de su propia producción, gracias a la subcontratación que obtiene de pequeñas empresas. El segundo es un exportador que cuenta con tres trabajadores dedicados al etiquetado de los zapatos que le suministran otras fábricas. La primera exporta principalmente a Estados Unidos, Canadá, Gran Bretaña, Irlanda, ...; la otra lo hace a Europa Central, Francia, República Federal Alemana, Holanda, Bélgica...

16 Según la información que hemos podido recabar, sólo cinco empresas: «Indexport, S.L.», «Cuatro Export, S.L.», «Navas Diego y Cía, S.L.», y la exportadora «INCAMA, S.L.», en el Vall d'Uixó; y «Ernesto Segarra, S.A.», en Almenara, además de «IMEMEL, S.A.», cuentan con un importante volumen de ventas y con clientela propia. También las empresas de Borriol, propiedad de la familia Sala, deben contar con sus propios clientes. 
de que parte de la oferta de trabajo sumergido está generada por el paro, que afecta a un buen número de trabajadores del sector calzado castellonense, especialmente de la Vall d'Uixó.

\section{CUADRO IV}

Paro en la industria del calzado de la Vall d’Uixó

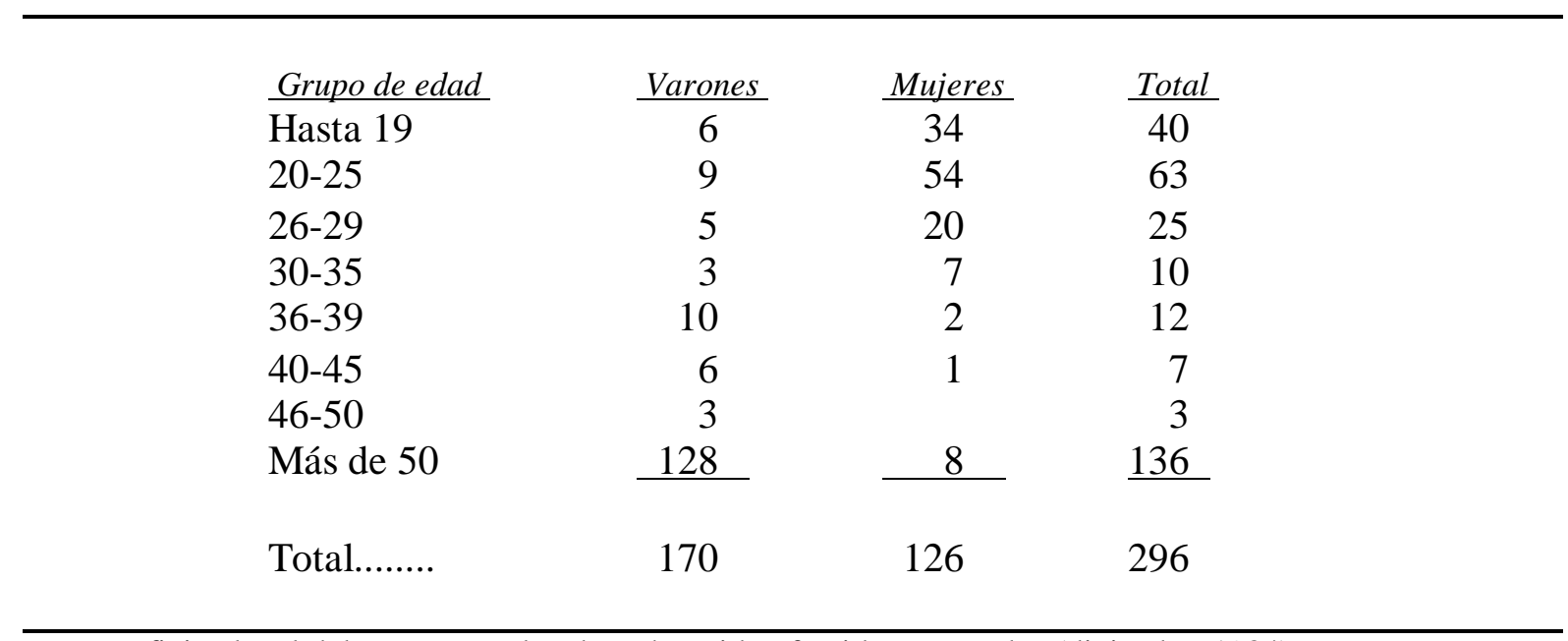

Fuente: oficina local del I. N. E. M., los datos han sido ofrecidos agrupados (diciembre 1984)

El paro en la rama del calzado ocupa en esta ciudad el tercer puesto, detrás de la «construcción» y del grupo «sin empleo anterior», a quienes no se les puede considerar parados por no haber desempeñado ninguna actividad. Como puede apreciarse en el cuadro IV, la mayor parte de los parados están en plena vida activa, más de la mitad no supera los cuarenta años de edad. Se observa un notable desequilibrio entre varones y mujeres, éstas son mayoría en las edades jóvenes (aproximadamente el 70\% de las mujeres tiene menos de veinticinco años, y el $85,7 \%$ no ha cumplido los treinta); todo lo contrario ocurre con los hombres, las tres cuartas partes del paro masculino se concentra en el grupo de más de cincuenta años, muchos de ellos son operarios acogidos a la regulación de empleo en la mayor empresa del calzado, en espera de la jubilación. Esta distribución del paro nos hace sospechar que la mayoría, si no todas las jóvenes menores de treinta años, trabajan en talleres clandestinos o aparando en sus propios domicilios. Lo mismo sucede con los varones de edades jóvenes; mientras que para los parados con más de cincuenta años -el 45,9\% del total- es más difícil encontrar algún tipo de trabajo, aunque no debe descartarse la posibilidad de que trabajen «por horas» en talleres o fábricas de calzado.

La única posibilidad de quienes han perdido su empleo, o de quienes lo buscan por primera vez, es practicar el trabajo a domicilio y/o ingresar en una fábrica clandestina. Los parados, tanto los que no perciben seguro de desempleo como los perceptores del mismo, constituyen un colectivo apto para efectuar trabajos no declarados. Es decir, las dificultades que encuentran los más 
jóvenes para acceder a un puesto de trabajo -incluso les resulta difícil entrar en un taller clandestino- y la imposibilidad de encontrar uno nuevo por parte de aquéllos que lo perdieron, favorecen la situación de los empresarios clandestinos que imponen sus condiciones, de manera que los trabajadores deben aceptarlas tácitamente, de lo contrario, como se les advierte, «si no estáis contentos, otros con gusto harán ese trabajo». Ante esta situación, ¿qué puede hacer el trabajador, si no aceptar, sumiso, el trabajo que ha ofrecido su patrono? Trabajan con un horario muy intenso, con jornadas interminables, incluso domingos y festivos, para poder terminar un pedido; si el obrero se niega o no acude al trabajo cuando el empresario lo requiere, éste no está obligado a pagarle ya que ningún vínculo jurídico les une.

Por otra parte, debido a las cada vez mayores necesidades de la sociedad de consumo, muchos trabajadores legales desean aumentar sus ingresos, lo que hacen en el trabajo sumergido, bien en su domicilio bien haciendo horas en un taller clandestino o en empresas «legales». Con frecuencia, trabajadores especialistas (mecánicos, cortadores, aparadoras, etc.) cuando terminan su jornada laboral, acuden a otras empresas a trabajar unas horas; de esta forma obtienen un complemento a sus ingresos económicos, muy apetecidos sobre todo al no tener que declararlos. Así, pues, el trabajo clandestino también está vinculado al doble trabajo; el primer trabajo, en una empresa legal, les da seguridad en el empleo, les ofrece asistencia sanitaria y les garantiza la futura pensión: mientras que el segundo trabajo, el sumergido, les permite obtener una renta superior ${ }^{17}$.

En cualquier caso, ya sean parados o activos pluriempleados, el empresario cuenta con una mano de obra dócil, lo cual es muy deseable desde su punto de vista, ya que no encuentra obstáculos a su tarea en los sindicatos, en convenios colectivos, no corre el peligro de huelgas $\mathrm{y}$ conflictos sociales ${ }^{18}$, queda libre de las reglamentaciones laborales que regulan las relaciones entre el trabajador y la empresa, relativos a duración de la jornada laboral, antigüedad, permisos, etc. De esta forma, el trabajador clandestino está inevitablemente sometido a una explotación, a contrataciones abusivas, que han llevado a algunos autores a hablar del «Tercer Mundo» ${ }^{19}$.

17 Este aspecto del doble trabajo ya fue señalado por Andrea Saba en el caso de la industria sumergida italiana. Véase a este respecto SABA, A.: La industria subterránea: un nuevo modelo de desarrollo, Institució «Alfons el Magnànim», Diputació de València, 1981, p. 152.

18 Aunque en 1977, la huelga del sector calzado en el Valle del Vinalopó se extendió a los trabajadores a domicilio. Pero, después la unidad del movimiento se rompió por estos mismos trabajadores. GÓMEZ PEREZAGUA, R.: «Estructura empresarial y economía oculta», InformaciónComercial Española, n. ${ }^{\circ}$ 587, julio 1982, p. 116.

19 Enric Sanchis, al referirse al trabajo clandestino, afirma que los empresarios buscan el «tercer mundo en casa». SANCHIS GÓMEZ, E.: El trabajo a domicilio en el País Valenciano, Instituto de la Mujer, Ministerio de Cultura, Madrid, 1984, p. 221. 


\section{EMIGRACIÓN EMPRESARIAL}

Otra de las respuestas de los empresarios ante la crisis ha sido la descentralización espacial. Desde la crisis se ha reducido considerablemente el nivel de empleo en el principal centro zapatero de la provincia, al tiempo que se ha potenciado en otras localidades. Este fenómeno se observa al analizar la distribución geográfica de la industria y las inversiones en ampliaciones y nuevas industrias de los últimos años.

\section{CAMBIOS RECIENTES EN LA DISTRIBUCIÓN DE LA INDUSTRIA}

En el cuadro V se resume la distribución de la industria del calzado (incluida la producción de alpargatas) de la provincia en los últimos diez años. Para su elaboración hemos consultado los listados del I.N.S.S., con los que se puede conocer el número total de empresas, no así el tipo de producción que realizan; la localidad donde se encuentran, y el número de trabajadores de cada una de ellas; los correspondientes a 1971 y 1979 han sido facilitados por don Enrique Domínguez ${ }^{20}$; los de 1982 han sido obtenidos según recuento personal del listado de dicho año.

\section{CUADRO V}

Distribución geográfica de la industria del calzado

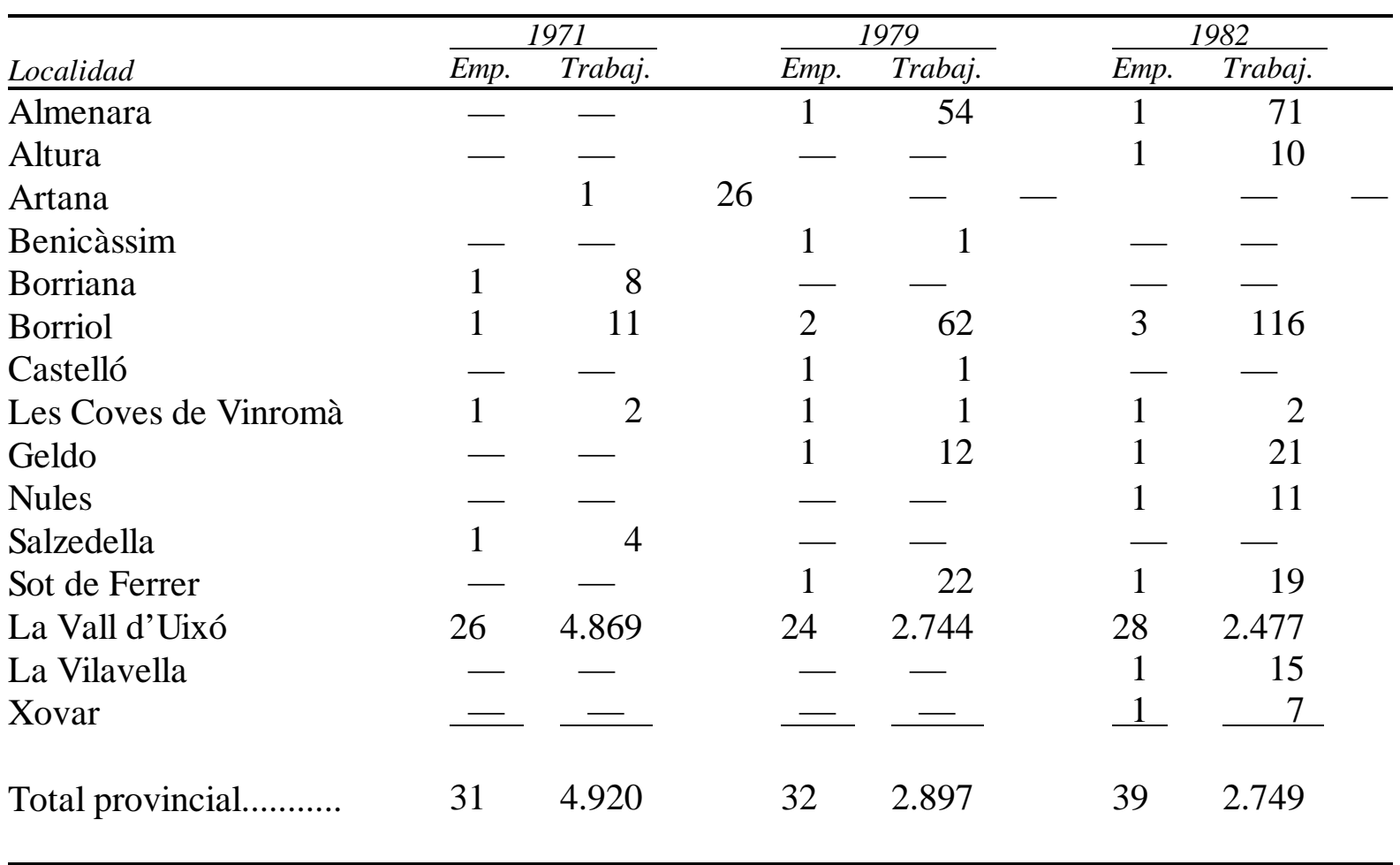

Fuente: Listados del I. N. S. S.

20 Agradecemos a don Enrique Domínguez su amabilidad, dedicación y colaboración prestadas. 
Como puede apreciarse en el cuadro, la Vall d'Uixó se constituye en centro de máxima importancia, pues en su área municipal concentra más del $70 \%$ de los establecimientos, con un empleo superior al $90 \%$ de los puestos de trabajo del sector de la provincia. Su especialización hace que la mayor parte de sus 26.437 habitantes (en 1981) dependan directa o indirectamente de la evolución del negocio zapatero. El resto de la industria está muy disperso (véase la figura) en núcleos de escasa importancia, destacando Borriol, que reúne tres fábricas especializadas en la fabricación de alpargatas, empleando a un total de 116 trabajadores. La tradición artesano-industrial de esta localidad se remonta a comienzos del siglo XX, pues en 1927 contaba con seis alpargateros. El desarrollo que ha alcanzado en nuestra centuria no deja de ser curioso si tenemos en cuenta el tipo de calzado fabricado, en una época en que la demanda del mercado se dirige hacia modelos de mayor calidad.

Junto a la Vall y Borriol, la industria del calzado también está presente en les Coves, cuya pequeña fábrica de alpargatas, en la que trabajan dos operarios, se instaló a mediados de siglo. Pero al margen de estos tres municipios en los que desde hace años hay actividad zapatera, en otros ha desaparecido, en el caso de la Salzedella, Castelló, Borriana o Artana. Mientras, desde hace pocos años se han instalado fábricas en núcleos sin indicios de actividad en épocas anteriores. La iniciativa ha partido de empresarios de la Vall d'Uixó; las inversiones -en algunos casos se trata de una auténtica emigración empresarial- que éstos han efectuado en otros municipios de la provincia, incluso en les Valls (Camp de Morvedre), tiene su explicación en los beneficios que obtienen en terrenos más baratos y en el menor coste de la mano de obra. En efecto, en estos núcleos, pueblos con escasos recursos económicos, con una agricultura predominantemente de secano y escasa industria ${ }^{21}$, como ha señalado Houssel al referirse a la instalación de empresas en medio rural $^{22}$, el empresario se encuentra con una mano de obra sin cualificación, que presenta la ventaja de aceptar salarios poco elevados y de ser poco reivindicativa, los campesinos se convierten en obreros, aceptando bajas remuneraciones que les parecen superiores a las rentas obtenidas con la economía tradicional agraria; en definitiva el empresario obtiene una mano de obra barata y dispuesta a trabajar en las condiciones que se le impongan.

El fenómeno de la difusión de industrias en medio rural, frecuente en otros países europeos desde mediados de siglo $^{23}$, adquiere cierta relevancia en

$21 \quad$ A este respecto, la única expección la constituyen los municipios de les Valls y Moncofa, con un importante monocultivo naranjero. Posiblemente por esta razón los empresarios que abrieron la fábrica de les Valls han vuelto a la Vall d'Uixó, pues en plena campaña naranjera había dificultades para conseguir mano de obra.

22 HOUSSEL, J. P.: «Les industries autochtones en milieu rural», Revue de Géographie de Lyon, 1980/4, pp. 305-341.

23 HOUSSEL, J. P.: «L' 'industrialisation spontanée face a la crise de 1973 en Europe occidentale», Revue de Géographie de Lyon, 1984/4, pp. 333-346; «Auto-developpement et amenagement en milieu rural en France et en Espagne», en Coloquio Hispano-Francés sobre Espacios Rurales, Instituto de Estudios Agrarios, Pesqueros y Alimenticios, Madrid, 1984, vol. 1, pp. 391-403. 


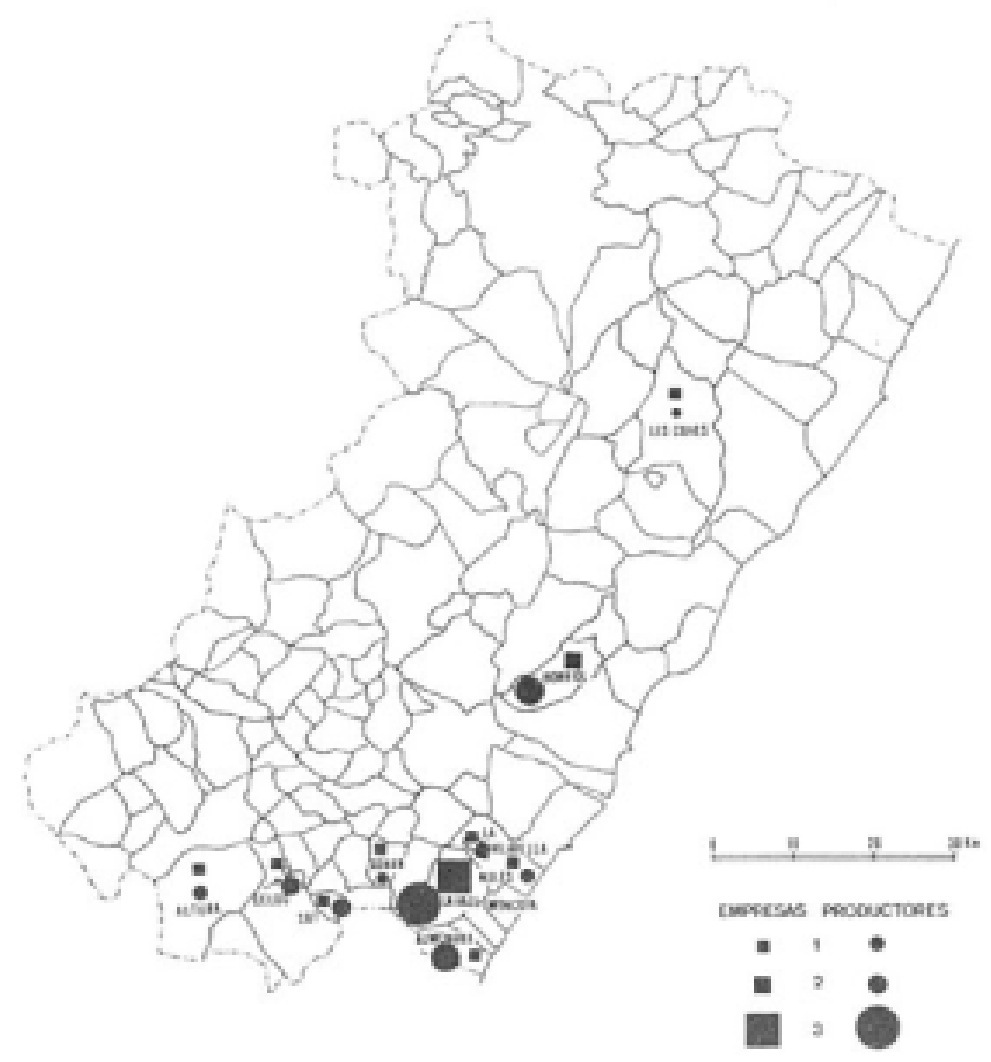

FIGURA: Localización de la industria del calzado, en 1982. Tamaños proporcionales al número de empresas y productores; en empresas: 1 una empresa, $2=$ tres, $3=$ veintiocho; en productores: $1=1=$ diez trabajadores, $2=$ veinte, 3= más de dos mil. 
nuestra provincia en fecha reciente. El primer desplazamiento se dirigió a Almenara, donde un ex-operario de la antigua Segarra instaló una pequeña fábrica. A raíz de la crisis de la mayor empresa del calzado, el director del Consejo de Administración en abril de 1975 -un año antes de la suspensión de pagos- vendió sus acciones, instalando ese mismo año una fábrica de curtidos en Nules ${ }^{24}$ y adquiriendo la fábrica de calzado de Almenara a su antiguo dueño (su ex-operario), mientras éste creaba una moderna empresa en la Vall d'Uixó. Los dos establecimientos funcionan con operarios cualificados de la Vall, que abandonaron la empresa en crisis. En 1979 otros empresarios instalaron nuevas industrias en Geldo y Sot de Ferrer, en un momento en que sus establecimientos de la Vall estaban atravesando serias dificultades. Más recientemente se han creado otras fábricas en localidades próximas a la Vall, es el caso de la Vilavella, Xovar y Moncofa, esta última no aparece recogida en el cuadro V por haberse instalado en 1983, por esa misma razón sólo la indicamos en la figura; o, un poco más alejadas, en Altura. En estos casos las han levantado ex-operarios de Vall que trabajaban en las empresas de mayores dimensiones. Paralelamente a la migración de las fábricas, en la propia Vall d'Uixó, como ya se ha puesto de manifiesto, han surgido un gran número de pequeños establecimientos, también de la mano de antiguos ex-operarios.

\section{INVERSIONES}

Las inversiones han sido obtenidas de los datos publicados por el Ministerio de Industria $^{25}$. La contabilización está hecha a partir de inscripciones definitivas, es decir, ya realizadas. El análisis evolutivo de las inversiones presenta un inconveniente: los frecuentes cambios de criterio adoptados por la publicación, que ha venido aumentando los umbrales de las inversiones públicas. En consecuencia cabe admitir que muchas inversiones no han sido contabilizadas porque debieron ser inferiores a las cantidades que en cada momento fijaba la publicación; además, es de suponer que parte de los valores declarados deben estar por debajo de los reales ${ }^{26}$, al margen de ocultaciones, sin duda frecuentes.

Casi todas las inversiones se han destinado a la ampliación de las empresas, con un desembolso de 186 millones de pesetas, mientras la creación de nuevas industrias sólo ha representado el 12,6\% del capital invertido; aunque, como hemos señalado antes, las cifras reales deben ser bastante mayores. En el período que analizamos se pueden distinguir dos etapas con características

24 VALENCIA SEMANAL: «Los zapatos del franquismo», 1977.

25 MINISTERIO DE INDUSTRIA: Servicios de publicaciones: Economía Industrial, revista mensual.

26 Esta cuestión ha sido señalada en otros estudios:

BERNABÉ MAESTRE, J. M.: La industria del calzado..., ob. cit., p. 69.

GOZÁLVEZPÉREZ, V.: La industria de esteras y alfombras en Crevillente, Círculo de Economía, Colección de estudios de Economía Regional, n. ${ }^{\circ}$, Alacant, 1975, p. 30. 


\section{CUADRO VI}

Inversiones en la industria del calzado de la provincia de Castelló

\begin{tabular}{|c|c|c|c|c|c|}
\hline \multirow[b]{2}{*}{ Año } & \multicolumn{2}{|c|}{ Ampliaciones } & \multicolumn{2}{|c|}{ Nuevas industrias } & \multirow[b]{2}{*}{ Inversión total } \\
\hline & $N .^{o}$ & $\begin{array}{c}\text { Valor } \\
\text { (miles de pesetas) }\end{array}$ & $N .^{o}$ & $\begin{array}{c}\text { Valor } \\
\text { (miles de pesetas) }\end{array}$ & \\
\hline$\overline{1967}$ & 2 & 29.805 & & & 29.805 \\
\hline 1968 & 1 & 19.075 & & & 19.075 \\
\hline 1969 & 1 & 3.544 & & & 3.544 \\
\hline 1970 & 2 & 45.135 & & & 45.137 \\
\hline 1971 & 3 & 1.584 & & & 1.584 \\
\hline 1972 & 2 & 37.120 & & & 37.120 \\
\hline 1977 & & & 1 & 8.880 & 8.880 \\
\hline 1978 & 1 & 5.146 & & & 5.146 \\
\hline 1979 & 2 & 12.782 & 3 & 17.961 & 30.743 \\
\hline 1983 & 2 & 31.725 & - & & 31.725 \\
\hline Total & 16 & 185.918 & 4 & 26.841 & 212.759 \\
\hline
\end{tabular}

Fuente: Ministerio de Industria: Economía Industrial, revista mensual. Elaboración propia.

bien distintas: la primera, hasta la crisis de mediados de los setenta, la podríamos denominar como «la etapa de las ampliaciones», el conjunto de las inversiones de este período se orienta hacia ese capítulo; y, una segunda etapa, hasta la actualidad, en la que las ampliaciones se ven acompañadas de la creación de nuevas industrias, con un mayor desembolso de capital por parte de las ampliaciones. En esta segunda etapa ha disminuido la inversión total, el sector se ha gastado poco más de la mitad $(56,1 \%)$ de lo invertido en la etapa anterior.

Como se puede apreciar en el cuadro VII, las inversiones han sufrido variaciones a lo largo del tiempo; en los primeros años las únicas registradas (y sólo en el capítulo de ampliaciones) eran las de la Vall d'Uixó, concretamente en la empresa «Silvestre Segarra e Hijos, S.A.»; debemos precisar que en 1971, también hubo inversiones en Almenara y Borriol, aunque debe tratarse de un error. Desde hace unos años, coincidiendo con la crisis de la mayor empresa del sector, las inversiones se han ido desplazando hacia otros municipios, con creación de nuevas industrias en Borriol (1977). Geldo y Sot de Ferrer (1979), que junto con la construcción de otra en la Vall d'Uixó, representan una inversión de 27 millones de pesetas; y ampliaciones en la Vilalella y Borriol (1983), que han supuesto un gasto superior a los 31 millones de pesetas, mientras la Vall d'Uixó ha mantenido tasas de inversión aceptables en 1978 y 1979.

En definitiva, las inversiones de calzado en la provincia de Castelló han manifestado un decaimiento en los últimos años; desde mediados de los seten- 


\section{CUADRO VII}

Distribución espacial de las inversiones

(en miles de pesetas)

\begin{tabular}{|c|c|c|}
\hline Localidad & $\underline{1967-1972^{27}}$ & $\underline{1977-1983}$ \\
\hline La Vall d'Uixó & 135.971 & 23.081 \\
\hline Borriol & 201 & 28.155 \\
\hline La Vilavella & & 12.450 \\
\hline Geldo & & 5.130 \\
\hline Sot de Ferrer & & 4.383 \\
\hline Almenara & 93 & 3.295 \\
\hline Total................. & 136.265 & 76.494 \\
\hline
\end{tabular}

Fuente: la misma del cuadro anterior. Elaboración propia.

ta sólo se ha invertido poco más de un tercio $(35,9 \%)$ de las inversiones efectuadas en el período 1967-1983. Es muy importante destacar que, al mismo tiempo, se ha producido un desplazamiento inversor ${ }^{28}$ hacia localidades situadas alrededor de la Vall d'Uixó, donde se han creado nuevas industrias a iniciativa de empresarios de este centro zapatero, que todavía conserva un notable peso específico dentro del sector. Esta descentralización espacial, estudiada por Ybarra en el caso de la industria del calzado alicantino, se enmarca dentro del proceso de difusión de industrias en medio rural que viene produciéndose desde hace años en los países de Europa Occidental. Constituye, junto con la expansión del clandestinaje, la readaptación espontánea de los empresarios a la crisis, en un intento de reducir o mantener los costes, ya que en los nuevos municipios los niveles salariales son menores que los del centro de difusión por razones de duplicidad agricultura-industria, mayor disponibilidad de mano de obra, desinformación laboral y social, etc.

\section{REFLEXIONES SOBRE EL COMPORTAMIENTO DEL SECTOR EN LOS ÚLTIMOS AÑOS}

Como conclusión podemos decir que la industria castellonense del calzado, caracterizada por la excesiva fragmentación en talleres muy pequeños -más de la mitad de los establecimientos cuentan con menos de diez

27 Las cifras de Borriol y Almenara corresponden a 1971, aunque en esa fecha la publicación sólo registraba las inversiones superiores al millón de pesetas en estas poblaciones se anotaron 201.000 y 93.000 pesetas, respectivamente. Debe tratarse de un error, con todo, también hemos contabilizado estas inversiones.

28 Este desplazamiento inversor ha sido detectado en el caso de la industria del calzado alicantino. Véase YBARRA PÉREZ, J.A.: «La reestructuración espontánea...», ob. cit., p. 499. 
operarios-, dirigida por empresarios sin la adecuada cualificación profesional, y ante la ausencia de medidas coherentes por parte de la Administración, se ha inclinado por la utilización del trabajo clandestino y la descentralización territorial, en un intento de conseguir una reducción de costes que le permita competir en el mercado. Frente a la crisis los empresarios han preferido esta «solución» a la inversión, que -como hemos visto- ha sufrido una fuerte contracción desde mediados de los años setenta. Examinemos a continuación algunos de los problemas que tiene planteados la industria del calzado como consecuencia de su reciente comportamiento y de sus propias características estructurales.

El minifundismo empresarial dificulta la incorporación de tecnologías avanzadas, la obtención de una explotación óptima, así como la escasez de recursos para aprovisionamiento de materias primas. Es decir, impide llevar a cabo el aumento de la productividad sobre la base de la renovación del equipo, nuevos métodos de trabajo, etc., frenando la expansión de la industria, especialmente de cara a la exportación.

Las pequeñas empresas, incapaces de atender a la comercialización de sus productos, trabajan subcontratadas por empresas productoras y comercializadoras, cuya producción final y cuyas ventas están fuertemente mediatizadas por firmas extranjeras. Nuestra producción se caracteriza por la falta de creatividad; nuestros fabricantes se inspiran, cuando no copian, modelos especialmente italianos, para ellos es lo más cómodo ya que eliminan parte de las preocupaciones al tiempo que ahorran inversiones en diseño. Ahora bien, la dependencia que conlleva esta forma de producción repercute negativamente en el sector, pues trabajando para casas extranjeras, nuestros zapatos, sin modelos propios, difícilmente podrán obtener un puesto destacado en el mercado internacional. Pero lo más grave es que los importadores, que imponen a nuestros empresarios los modelos y el precio a que deben fabricarlos, y que buscan su propio beneficio, pueden cambiar de suministradores con gran rapidez cuando les convenga. Esta circunstancia hace que nuestra producción sea altamente vulnerable; el día que las comercializadoras encuentren otros productores que puedan ofrecerles zapatos a más bajo precio nuestro sector se verá seriamente amenazado, ya que las empresas quedarían sin mercado al estar éste controlado por aquéllas.

Los empresarios deberían tecnificar el proceso productivo y esto sólo es posible con fuertes inversiones que ellos no pueden realizar dadas las características actuales del sector. El camino a seguir es -como ya señaló hace tiempo Sintes Obrador para el calzado alicantino ${ }^{29}$ - la «concentración empresarial», entendida como cooperación de las empresas en una serie de funciones, como son: comercialización, investigación, diseño y moda, etc., a las que no pueden atender por sí solas. Sin embargo, esto no podría lograrse sin la desaparición de la economía sumergida.

29 SINTES OBRADOR, F.: «Alicante y su industria: pasado, presente y futuro de la industria del calzado», Información Comercial Española, n. ${ }^{\circ}$ 485, enero 1974, pp. 199-222. 
El fenómeno del clandestinaje se ha difundido ampliamente en el principal centro zapatero, y también por los nuevos núcleos productores, donde existe la posibilidad de utilizar trabajo oculto, incluso, con mayor profusión que en el centro debido a la complementariedad entre agricultura e industria. Constituye una falsa respuesta a la crisis que no hace sino prolongar la agonía del sector; como señala Enric Sanchis, «los empresarios escapan a la crisis por la puerta de detrás» ${ }^{30}$, de esta forma obtienen unos costes bajos y mantienen la competitividad de sus productos, pero sólo -como señala el mismo autor- momentáneamente, ya que la guerra de los precios siempre la ganarán los nuevos países productores. Esta «solución» adoptada por los empresarios dificulta la consolidación de las empresas, ya que la práctica del trabajo oculto impide la capitalización de los establecimientos.

La economía sumergida es uno de los principales problemas del sector, que impide su racionalización. Actúa de forma negativa por cuanto que: constituye un fraude al Estado por la evasión de impuestos; los artículos fabricados en empresas clandestinas escapan a los controles de calidad; desde el punto de vista de las relaciones laborales, el trabajador está sometido a una explotación; además este tipo de establecimientos ejercen una competencia desleal a las empresas legales, cuyos costes son mucho más elevados, pudiendo por contagio generar un proceso de ocultación incontrolable. Por estas razones, se requieren soluciones al problema; las medidas a adoptar no deben ser de carácter represivo ${ }^{31}$, combatir la economía sumergida puede acentuar los problemas de desocupación, y hay que tener presente que «esa economía sumergida, incluso en su peor aspecto, es un colchón, es una válvula de escape que permite que más o menos gente trabaje y que, por tanto, de esa forma escape a la

30 SANCHIS GÓMEZ, E.: «La industria subterránea y crisis económica en el País Valenciano (el final de un momento de crecimiento)», Información Comercial Española, n. ${ }^{\text { }}$ 587, julio 1982, p. 129.

31 En esto coinciden economistas, sociólogos y empresarios. Véanse a este respecto: CERÓN AYUSO, J. L.: «Perspectiva empresarial ante el fenómeno del crecimiento de la economía oculta en España», Boletín de Estudios Económicos, n. ${ }^{\circ}$ 117, Universidad de Deusto, Bilbao, 1982, p. 436; el artículo de GÓMEZ PEREZAGUA, R.: ob. cit., 117; el de SANCHIS GÓMEZ, E., publicado en Información Comercial Española, p. 130; o el de VÁZQUEZ ARAGÓ, C. y TRIGO PORTELA, J.: «Las vías de transformación de la economía formal en irregular (de la explicación teórica a la evidencia empírica)», Información Comercial Española, n. ${ }^{\circ}$ 587, julio 1982, p. 89. 
absoluta desesperación» ${ }^{32}$. La solución al problema no está en acabar con el trabajo clandestino, sino, por el contrario, en adoptar medidas que estimulen a los empresarios en la inversión y que se incorporen a la legalidad. Tampoco se trata de hacer emerger esta economía sin más, sino que, para hacerla emerger, se debe reflexionar sobre las circunstancias que la hacen posible, la política fiscal, y en concreto sobre las cuotas a la Seguridad Social. Si los elevados impuestos a la Seguridad Social motivan, en parte, la sumersión, la solución no está en obligar a los empresarios clandestinos a que den de alta a sus trabajadores. Si así se hiciese, la situación que se podría originar en el sector sería catastrófica, los empresarios se verían obligados a subir el precio de venta de sus productos para compensar los mayores costes que se derivarían de hacer efectivas las cotizaciones a la Seguridad Social, disminuiría su competitividad y, en consecuencia, muchas empresas desaparecerían. Sería, pues, apropiada una racionalización de la cotización a la Seguridad Social, que discrimina a las empresas de este sector por su abundante mano de obra, y que «obliga» a un gran número de pequeñas empresas a actuar de espaldas a la Administración.

32 SÁNCHEZ AYUSO, M. «Economía Golfa», EL PAIS, año VI, n. ํ 1.521, 27 de marzo de 1981, p. 46. 